\section{Recurrent Auricular Keloids during Pregnancy}

Hyung-Do Kim, So-Min Hwang, Kwang-Ryeol Lim, Yong-Hui Jung, Sung-Min Ahn, Jennifer Kim Song

Department of Plastic and Reconstructive Surgery, Good

Moonhwa Hospital, Busan, Korea

\section{Correspondence: So-Min Hwang}

Department of Plastic and Reconstructive Surgery, Good Moonhwa Hospital,

119 Beomil-ro, Dong-gu, Busan 601-803, Korea

Tel: +82-51-630-0199, Fax: +82-51-630-0145

E-mail:sm_hwang@hanmail.net

No potential conflict of interest relevant to this article was reported.

Received: 11 May 2012 • Revised: 5 0ct 2012 • Accepted: 6 0ct 2012 pISSN: 2234-6163 • elSSN: 2234-6171

http://dx.doi.org/10.5999/aps.2013.40.1.70 • Arch Plast Surg 2013;40:70-72

Copyright (C) 2013 The Korean Society of Plastic and Reconstructive Surgeons

This is an Open Access article distributed under the terms of the Creative Commons

Attribution Non-Commercial License (http://creativecommons.org/licenses/by-nc/3.o/)

which permits unrestricted non-commercial use, distribution, and reproduction in any

medium, provided the original work is properly cited.

A keloid is one of the most frustrating clinical problems in wound healing. Keloids form following dermal injury and exhibit exuberant and indefinite growth of collagen. Many theories have been propounded in trying to explain some of the vagaries of keloids. From one of the theories, keloid scars may develop at any age; patients between 10 and 30 years of age (reproductive age) are the most affected population, and there may be a hormonal influence because keloid scars tend to grow during puberty and pregnancy, and resolve during menopause [1]. In our experience, pregnancy-related recurrent keloids have arisen from the ear, despite the patient's successful completion of our treatment. The case presented here illustrates the possible connection between keloid formation and hormonal changes during pregnancy.

A 27-year-old pregnant female visited our clinic due to progressive growth of her left auricular keloid. Three years prior to the visit, she had developed a scar on her left auricle after treatment for acute inflammation caused by an ear piercing procedure at a nonmedical institute. She showed no other particular medical history. She also reported that the lesions appeared and became larger after the first trimester of pregnancy (Fig. 1). On physical examination, the left auricle showed a keloid of nearly circular appearance, approximately $2.2 \mathrm{~cm}$ in diameter, with a mean thickness of about $1.5 \mathrm{~cm}$, extending from the superior pole of the auricle down to the middle ear. The skin surface of the keloid was irregular and showed dispersed minute superficial ulcer with itching sensation.

Because of pregnancy, we waited to perform a core extirpation of the keloid until 6 months after delivery. Compression on the auricle was performed postoperatively in combination with the application of scar care ointment. Even after 1 month, the clinical result remained obviously acceptable where the core extirpation had been performed.

Two years later, the patient returned with a huge enlargement of the left auricular keloid. Similar to the previous keloid, it appeared and became bigger $(2.2 \times$ $1.7 \mathrm{~cm}$ ) simultaneously with child bearing. She remembered that the keloid started to enlarge rapidly in her first trimester of her second pregnancy, with mild itching and redness. She was asked to return after her delivery (Fig. 2).

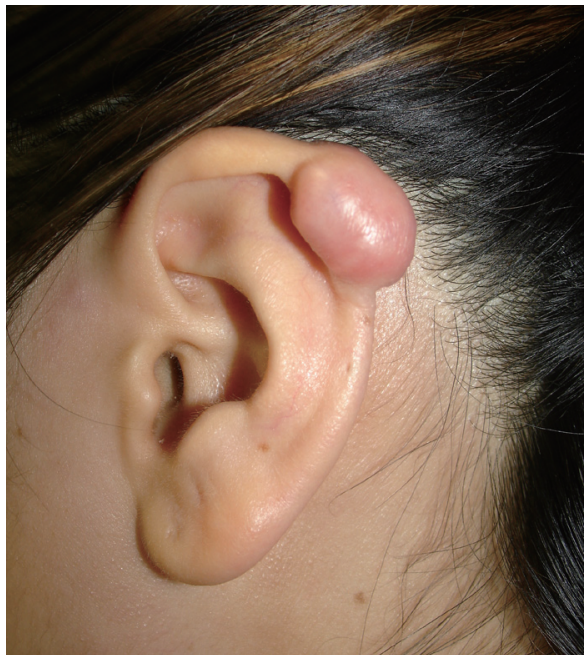

Fig. 2.

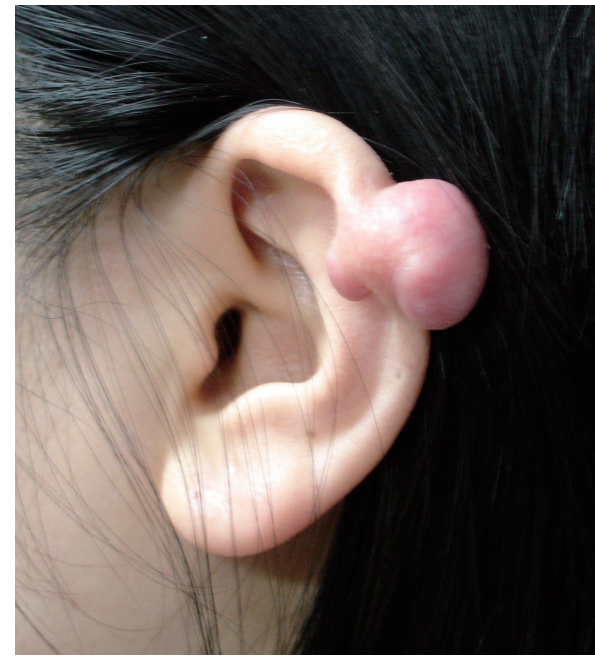

Fig. 1.
Preoperative photo showing a keloid after the second pregnancy. 

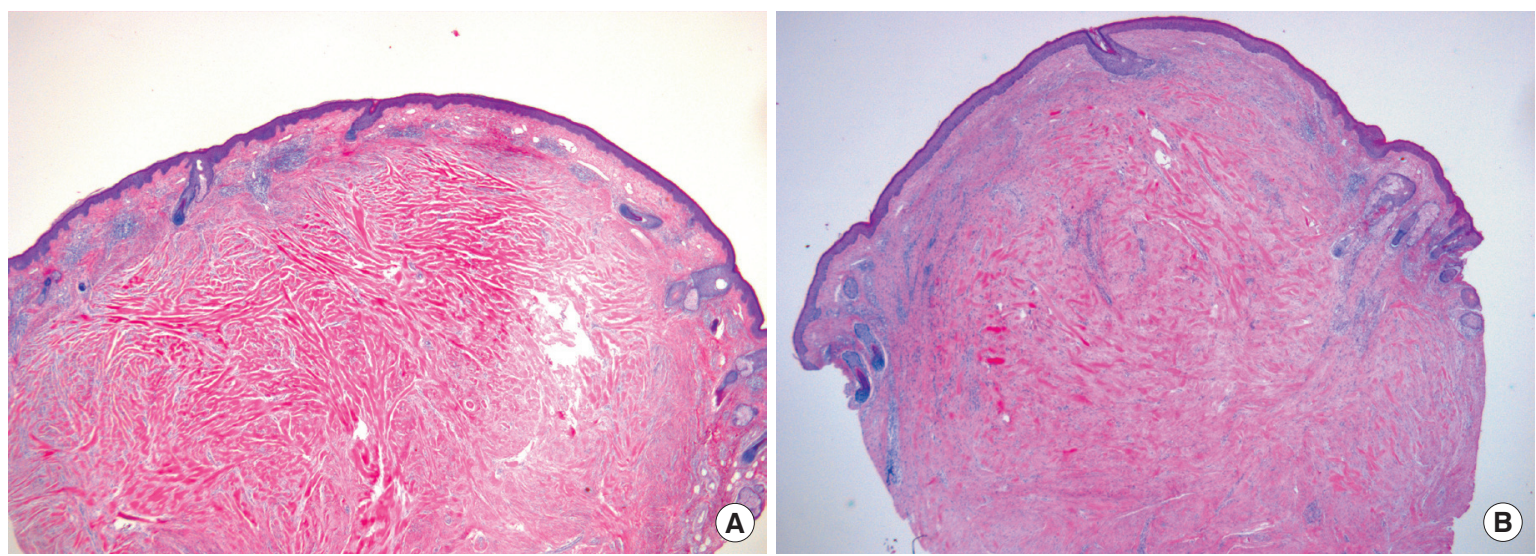

Fig. 3.

(A) First pregnancy. Histopathologic photograph showing thepresence of keloidal collagen and a prominent fascia-like fibrous band, which confirms the diagnosis of keloid $\left(H \& E_{1} \times 100\right)$. (B) Second pregnancy. Histopathologic photograph showing nearly the same appearanceof keloidal collagen and a prominent fascia-like fibrous band,as in the first pregnancy $\left(H \& E_{1} \times 100\right)$.

Accordingly, she underwent core extirpation 6 months after her second delivery, and compression treatment was performed postoperatively in combination with the application of scar care ointment. The patient was satisfied with the results at postoperative 4 months.

The scar tissues, sized at $2.0 \times 1.5 \mathrm{~cm}$ and $2.0 \times 1.0$ $\mathrm{cm}$, were excised over repeated core extirpations. In both histopathologic reports, no flattening of the overlying epidermis, presence of keloidal collagen, or a prominent fascia-like fibrous band occurred, which confirms the diagnosis of keloid (Fig. 3).

Up to the present, the clinical outcome has shown a clean and satisfactory auricle. The patient has not undergone another pregnancy nor presented any additional keloid growth; specifically, she has reported that her lobular keloid remains inactive.

In most known series of keloids, there is a higher incidence in women, with an apparent peak in the immediate post-pubertal years. Lane et al. [2] reported in his study that those who had ear piercings at 11 years of age or above were more likely to develop keloids (80\%) than were those who had ear piercings under 11 years of age (23.5\%). Because of this observation, the possibility of a female hormonal influence on keloid formation has been advanced.

In a study of connective tissue tumors, Geschichter and Lewis [3], bioassayed a single keloid of an ear that had been preserved in formalin; they reported that this keloid tissue contained large amounts of estrogen and gonadotropic substances. However, no confirmation of their work has appeared in the literature. Jacobsson [4] reported a case of a woman whose 4-year-old scar became hypertrophic during pregnancy.

Reviewing the different actions of pregnancy hormones, it appears that estrogens are the hormones most likely involved in the keloidal tendency that may accompany pregnancy [5]. The ovaries and adrenal cortex of mature women produce estrogens. In pregnancy, the major site of production is the placenta. Our patient noted rapid enlargement and irritation of her keloid, which began in the first trimester of pregnancy. This supports our view on the effect of hormonal influence in scar or keloidal tissue during pregnancy, and agrees with the concept that regression of symptoms occurs after delivery.

It is known that auricular and lobular keloids appear on account of inflammation caused by an unhygienic ear piercing procedure. However, we report our treatment experience in a case with recurrent keloids during pregnancy after showing no particular change at the time of treating the inflammation. We conclude that pregnancy is the strongest risk factor for keloid recurrence in addition to the three clinical risk factors identified through a review of the literature: treatment history, timing of keloid growth, and timing of regression.

\section{References}

1. Brissett AE, Sherris DA. Scar contractures, hypertrophic scars, and keloids. Facial Plast Surg 2001;17:263-72.

2. Lane JE, Waller JL, Davis LS. Relationship between age of ear piercing and keloid formation. Pediatrics 2005;115:1312-4. 
3. Geschichter CF, Lewis D. Tumors of connective tissue. Am J Cancer 1935;25:630-55.

4. Jacobsson F. The treatment of keloids at Radium-hemmet, 1921-1941. Acta Radiol 1948;29:251-67.

5. Moustafa MF, Abdel-Fattah MA, Abdel-Fattah DC. Presumptive evidence of the effect of pregnancy estrogens on keloid growth: case report. Plast Reconstr Surg $1975 ; 56: 450-3$. 